\title{
EDITORIAL
}

Versão original

DOI: http://dx.doi.org/10.1590/So034-759020180601

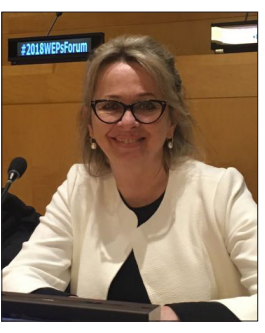

MARIA JOSÉ TONELLI Editora-chefe

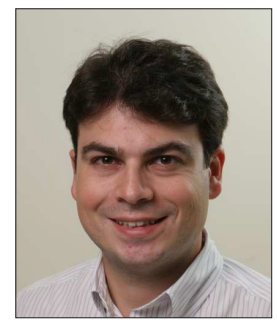

FELIPE ZAMBALDI Editor-adjunto

\section{INTEGRAÇÃO DA PESQUISA NA AMÉRICA LATINA}

O Congresso Red Pilar de Estudos Organizacionales (2018), realizado em setembro deste ano no Chile, nos impressionou ao demonstrar que vários países latino-americanos estão engajados em projetos e pesquisas nessa área. A articulação entre países de blocos regionais como a União Europeia tem contribuído para o fortalecimento da pesquisa pela fertilização cruzada que se origina dessas redes de pesquisa. Mais do que isso, tem permitido que os países que integram esse grupo possam se beneficiar, em políticas públicas, do conhecimento científico. Chaimovich (2008), da InterAmerican Network of Academies of Sciences (lanas), enfatiza que o fortalecimento da rede é fundamental para a diminuição da pobreza e do desemprego na América Latina. Sem ciência, diz Chaimovich (2008), os governos não têm onde se apoiarem para o desenvolvimento sustentável e transferências de tecnologias para a sociedade (Schwartzaman, 2008). Ainda que a América Latina tenha sofrido atrasos na sua internacionalização, é necessário que a ciência na região traga resultados sociais (Balán, 2008). Vários programas de pós-graduação, em diversas áreas, fazem intercâmbios há décadas, mas falta muito para alcançar todos os potenciais benefícios que uma maior integração poderia gerar. Em 2016, o Brasil hospedou, no Rio de Janeiro, o congresso dessa associação, mas não identificamos a participação da área de Ciências Sociais Aplicadas. Embora o lanas esteja mais voltado para a área de Ciências Médicas e Naturais, ele "visa fortalecer a ciência e a tecnologia a fim de avançar a pesquisa, o desenvolvimento e a equidade nas Américas” (IV Congresso, 2018), objetivo que faz sentido para todos os campos de conhecimento e também para a área de Administração, Contabilidade e Turismo.

Áreas da Administração, como Estudos Organizacionais, Marketing e Estratégia, têm feito seu papel. Os eventos da Red Pilar, em 2018, do Latin American and European Meeting on Organization Studies (Laemos, 2018), da Association for Consumer Research (ACR) e do Latin American Conference e Strategic Management in Latin America (SMLA), em 2017, contribuíram para essa aproximação. 0 The Business Association of Latin American Studies (BALAS), o Consejo Latinoamericano de Escuelas de Administración (CLADEA) e a Ibero American Academy of Management também têm feito esforços para essa integração. Chamamos a atenção, ainda, para um Fórum sobre o tema organizado pela $R A E$, “Estudios organizacionales en América Latina: Desafíos y possibilidades". Mas consideramos que a região, diante dos inúmeros problemas similares que enfrenta, poderia beneficiar-se ainda mais do conhecimento gerado em projetos de pesquisa conjuntos entre programas de pós-graduação, intercâmbio de pesquisadores e alunos, tanto em pesquisa básica como em pesquisa aplicada. Nesse espírito, a RAE mantém a publicação de artigos em espanhol, para que possamos estreitar os laços entre nós.

A última edição de 2018 está composta pelos artigos: “Cegueira ao patrocinador: Utilização de banners em eventos esportivos”, de Manuel Alonso dos Santos, Ferran Calabuig Moreno e Manuel Jesús Sánchez-Franco, “Novas formas de relatório corporativo: Informação sobre a pegada de carbono na Espanha”, de Carmen Raquel Córdova, Ana Zorio-Grima e María García-Benau, “Diversidade do 
conselho de Administração e a estrutura de capital”, de Edelcio Koitiro Nisiyama e Wilson Toshiro Nakamura, e "A importância do apego à marca para o engajamento em causas de responsabilidade social corporativa”, de Annaysa Salvador Muniz Kamiya, José Mauro da Costa Hernandez, Agnne Karoline S. Xavier e Débora Beserra Ramos.

Completam a edição a pensata "Decisões corporativas em grupo: Uma abordagem comportamental", de Lucas Ayres Barreira de Campos Barros, as resenhas dos livros 0 ardil da flexibilidade: Os trabalhadores e a teoria do valor, de Sadi Dal Rosso, elaborada por Maiara Marinho, e Coaching: O exercício da liderança, de Marshall Goldsmith, Laurence Lyons e Sara McArthur, escrita por Danielle Marques dos Ramos Monteiro, além das indicações bibliográficas “Análise sociológica do discurso e grupo de discussão: Práticas da tradição espanhola de pesquisa qualitativa”, de Christiane Kleinübing Godoi, e "Narcisismo e performance da firma”, de Karen Kristina Ayala de Carvalho.

Boas festas!

Maria José Tonellii ${ }^{1}$ | ORCID: 0000-0002-6585-1493

Felipe Zambaldi ${ }^{1}$ | ORCID: 0000-0002-5378-6444

${ }^{1}$ Fundação Getulio Vargas

Escola de Administração de Empresas de São Paulo,

São Paulo, SP, Brasil

\section{REFERÊNCIAS}

IV Congresso. (2018). Recuperado de http://www.abc.org.br/evento/iv-assembleia-geral-da-rede-interamericana-de-academias-de-ciencias-ianas/

Balán, J. (2008). Universidade, pesquisa e desenvolvimento: 0 novo contexto. In S. Schwartzman (Org.), Universidades e desenvolvimento na América Latina: Experiências exitosas de centros de pesquisa. Rio de Janeiro, RJ: Centro Edelstein de Pesquisas Sociais. Recuperado de www.centroeldestein.org.br

Chaimovich, H. (2008). Apresentação. In S. Schwartzman (Org.), Universidades e desenvolvimento na América Latina: Experiências exitosas de centros de pesquisa. Rio de Janeiro, RJ: Centro Edelstein de Pesquisas Sociais. Recuperado de www.centroeldestein.org.br

Latin American and European Meeting on Organization Studies. (2018). Recuperado de https://www. egosnet.org/jart/prj3/egos/data/.../LAEMOS-2020_Call-for-Proposals.pdf

Schwartzaman, S. (2008). As universidades latino-americanas e sua contribuição para o desenvolvimento sustentável da região. In S. Schwartzman (Org.), Universidades e desenvolvimento na América Latina: Experiências exitosas de centros de pesquisa. Rio de Janeiro, RJ: Centro Edelstein de Pesquisas Sociais. Recuperado de www.centroeldestein.org.br

Red Pilar de Estudos Organizacionales. (2018). Recuperado de http://www.redpilares.net/Paginas/ inicio.aspx; https://www.congresoredpilares.com/redpilares 